\title{
Contribuição do pensamento de Paulo Freire para o paradigma curricular crítico-emancipatório
}

\author{
Marilia Gabriela de Menezes ${ }^{*}$, Maria Eliete Santiago * * \\ http://dx.doi.org/10.1590/0103-7307201407503
}

\section{Resumo}

Filósofos, educadores e curriculistas, comprometidos com o paradigma da educação emancipatória de vários países, compartiIham a ideia de que o pensamento de Paulo Freire está sempre em movimento e dialoga com diferentes questões contemporâneas, assim como traz elementos norteadores para a construção da teoria curricular crítica e eticamente empenhada na humanização dos sujeitos. Nessa direção, o presente artigo analisa os elementos que configuram a proposta educacional libertadora e o diálogo como uma das categorias fundantes do pensar freireano para tratar das questões sobre o currículo na perspectiva crítico-emancipatória. A pesquisa privilegia a abordagem de natureza qualitativa e elege, como procedimento investigativo, o estudo bibliográfico. Para a análise dos dados, toma como referência a técnica de Análise Temática na perspectiva de Laurence Bardin.

\section{Palavras-chave}

Paulo Freire, currículo crítico-emancipatório, proposta educacional libertadora, diálogo.

* Universidade Federal Pernambuco e Cátedra Paulo Freire/UFPE, Recife, PE, Brasil. mariliagabrielaufpe@gmail. com.

** Universidade Federal Pernambuco e Cátedra Paulo Freire/UFPE, Recife, PE, Brasil. mesantiago@uol.com.br. 


\title{
Paulo Freire's thought on the critical- emancipatory curriculum paradigm
}

\begin{abstract}
Philosophers, educators and curriculum experts committed to the paradigm of emancipatory education in several countries share the idea that the political-pedagogical thinking of Paulo Freire is always in motion and that it dialogues with various contemporary issues, thus providing guidance for the construction of a curriculum theory emancipatory and ethically committed to humanize each individual. This article analyzes the elements that shape a liberating educational proposition, showing the dialogue as one of the founding categories of Freire's thinking, appropriated to deal with curriculum issues in a critical-emancipatory perspective.
\end{abstract}

Keywords

Paulo Freire, curriculum critical-emancipatory, liberating educational proposal, dialogue. 


\section{Introdução}

As discussões no campo do currículo, cada vez mais, são ampliadas e aprofundadas, superando a concepção restrita e fragmentada, passando ele a ser visto como instrumento de ação política e pedagógica. Assim, retrata o conjunto de valores e interesses da sociedade como também a concepção de educação e de sujeito cuja materialidade ocorre na sala de aula. Essa perspectiva curricular tem sido fruto de várias contribuições da teoria crítica, dentre as quais destacamos, neste texto, as contribuições político-pedagógicas de Paulo Freire, mais especificamente, a categoria diálogo, entre aquelas consideradas fundantes do pensar freireano, para tratarmos das questões sobre o currículo na perspectiva crítico-emancipatória.

Realizamos um estudo bibliográfico das obras de Paulo Freire e de autores da teoria crítica do currículo, utilizando a Análise Temática (Bardin, 2008), por permitir evidenciar os núcleos de sentido que compõem os textos. Nessa direção, procedemos à leitura exploratória para construir uma compreensão dos significados e dos conteúdos, articulando as informações produzidas e estabelecendo interseções e relações entre os conceitos.

As ideias que fundamentam o currículo crítico-emancipatório tiveram início nos anos de 1970, nos Estados Unidos, com o movimento de “reconceptualização do currículo", originado na rejeição do caráter prescritivo e no reconhecimento do caráter político do pensamento e da prática curricular.

A década de 1970 foi marcada por importantes movimentos sociais e culturais e por um debate intenso no campo da educação, quando em diferentes países, como Estados Unidos, Inglaterra e outros da Europa, a produção acadêmica discutia as teorias educacionais, colocando em questão a teoria tradicional. Nos Estados Unidos, estudiosos como Henry Giroux e Michael Apple, influenciados pela teoria social europeia, pela psicanálise, pela nova sociologia da educação e pela pedagogia Paulo Freire criticaram a abordagem técnica do currículo e desenvolveram “[...] uma análise de forte cunho sociológico" procurando "mostrar como as formas de seleção, organização e distribuição do conhecimento escolar favorecem a opressão da classe e grupos subordinados" (Santos; Moreira, 1995, p. 50).

A Nova Sociologia da Educação (NSE), iniciada por Michael Young na Inglaterra, nos primeiros anos da mencionada década, constituiu-se na primeira corrente sociológica voltada para a discussão do currículo. Os sociólogos da NSE, primeiramente, questionaram o caráter elitista da educação britânica, em termos éticos, econômicos 
e políticos, e orientaram suas pesquisas para a formulação de políticas governamentais, intencionando superar essa realidade. Young (1989) defendeu que as questões curriculares precisavam ser analisadas em relação ao contexto sócio, histórico e econômico em que se situavam, para possibilitar a compreensão das relações de poder que permeavam o campo do currículo.

Nessa fase, merece destaque o evento que deu impulso ao movimento de reconceptualização do currículo, a I Conferência sobre Currículo, ocorrida na Universidade de Rochester, Nova Iorque, em 1973. 0 movimento expressava a insatisfação em relação à concepção técnico-linear do currículo, por ela não ser coerente com as ideias difundidas pelas teorias sociais, tais como a fenomenologia, a hermenêutica, o marxismo e a teoria crítica da Escola de Frankfurt (Silva, 2007).

Os teóricos da Escola de Frankfurt desenvolveram uma teoria que procurou desvelar e romper com as estruturas opressivas, objetivando contribuir para a emancipação humana e com a mudança social, na medida em que realiza uma análise crítica das relações sociais, superando os ditames da racionalidade positivista que sujeitava a consciência e as ações humanas ao imperativo de leis universais. Seus representantes argumentavam a favor do pensamento dialético, como pensamento crítico que supera a ideia positivista de neutralidade e se posiciona a favor da luta por um mundo melhor.

Segundo Giroux (1986), a Escola de Frankfurt, ao fundamentar o seu trabalho na crítica ao pensamento positivista, constrói uma teoria que tem implicações importantes para os teóricos que são críticos das teorias tradicionais da educação. De acordo com o autor, a teoria social desenvolvida pela Escola de Frankfurt contribui para compreender questões que envolvem o currículo em uma perspectiva emancipatória.

No Brasil, a partir dos finais dos anos de 1950, a educação, e particularmente a educação de adultos e a educação popular, encontrou em Paulo Freire a referência que formula as bases da educação libertadora como um paradigma que influencia o campo do currículo. A concepção freireana de educação, na qual as finalidades, os conteúdos, as ações estão articulados para possibilitar a humanização e a libertação dos sujeitos contribuiu na orientação das políticas curriculares, construindo um horizonte de possibilidades para a emancipação humana a serviço da transformação social. Nesse contexto de reconceptualização da teorização curricular, buscou-se superar os fundamentos das teorias tradicionais, caracterizadas pela aceitação, pelo ajuste e pela adaptação na sociedade vigente, e construir uma teoria crítica do currículo, pautada no questionamento e na modificação dessa sociedade. 
Saul (1998), ao discutir o currículo na perspectiva crítica, afirma que o pensamento de Paulo Freire constitui uma matriz importante, que fundamenta o paradigma curricular de racionalidade crítico-emancipatória. Segundo a autora, os elementos político-pedagógicos da educação libertadora contribuem para estabelecer uma relação dialética entre o currículo e o contexto histórico, social, político e cultural, ou seja, tratar o currículo na dimensão da totalidade em que os diferentes contextos, num processo dinâmico, se relacionam e se influenciam. Essa compreensão crítico-emancipatória possibilita situar o currículo na direção de um projeto social que contribua para a emancipação dos sujeitos.

O pensamento curricular crítico traz a presença de Paulo Freire no debate educacional e, no caso especifico do campo do currículo, influencia as políticas e as práticas curriculares. Desse modo, passamos a destacar os elementos que configuram a sua proposta educacional libertadora e o diálogo como categoria e dinâmica do seu pensamento.

\section{A perspectiva freireana de educação}

A contribuição de Paulo Freire para o campo do currículo foi tecida a partir da crítica à educação bancária e no movimento de superação pela formulação de uma educação libertadora que se realiza como "[...] um processo pelo qual o educador convida os educandos a reconhecer e desvelar a realidade criticamente” (Freire, 1985, p. 125).

A educação bancária, que tem por referência as teorias tradicionais do currículo, compreende os(as) estudantes como depósitos vazios a serem preenchidos por conteúdos do domínio exclusivo do(a) professor(a). Nessa concepção, o(a) estudante é percebido como alguém que nada sabe, como ser passível de adaptação e ajuste à sociedade vigente. A curiosidade e a autonomia vão-se perdendo na produção do conhecimento, uma vez que o conhecimento é narrado pelo(a) professor(a) como algo acabado, estático. Assim, expõe-se o(a) estudante a um processo de desumanização,

Dessa forma, os homens e as mulheres apenas vivem no mundo, mas não existem. Para Freire, o que possibilita a ação livre, criadora e determinadora das condições de existência é o desenvolvimento de consciência, capaz de apreender criticamente a realidade. Por isso ele critica esse tipo de educação que não permite a formação de consciência crítica, pois os(as) estudantes são estimulados a memorizar o conteúdo, e não a conhecê-lo, uma vez que não realizam nenhum ato cognoscitivo do objeto de conhecimento além do caráter verbalista, dissertativo, narrativo. Características 
típicas do currículo tradicional, afastadas da realidade existencial das pessoas envolvidas no processo educacional. Essa educação, assim como, o currículo, “[...] sugere uma dicotomia inexistente homens-mundo. Homens simplesmente no mundo e não com o mundo e com os outros. Homens espectadores e não recriadores do mundo" (Freire, 2001, p. 62). Nessa crítica à educação bancária e consequentemente ao currículo, Paulo Freire mostra que,

o currículo padrão, o currículo de transferência é uma forma mecânica e autoritária de pensar sobre como organizar um programa, que implica, acima de tudo, numa tremenda falta de confiança na criatividade dos estudantes e na capacidade dos professores! Porque, em última análise, quando certos centros de poder estabelecem o que deve ser feito em classe, sua maneira autoritária nega o exercício da criatividade entre professores e estudantes. 0 centro, acima de tudo, está comandando e manipulando, à distância, as atividades dos educadores e dos educandos. (Freire; Shor, 2008, p. 97).

O pensamento de Paulo Freire supera essa concepção bancária da educação, quando formula as bases para uma educação libertadora. Uma educação como prática da liberdade, fundamentada na teoria da ação dialógica, que substitui o autoritarismo presente na escola tradicional pelo diálogo democrático nos diferentes espaços de vivências e de aprendizagens. Esta educação exige que os homens e as mulheres estejam engajados na luta para alcançar a libertação, em um processo incessante de conquista que se dá na comunhão com os outros, o qual resulta de uma conscientização em que os homens e as mulheres (crianças, jovens e adultos) compreendem a sua vocação ontológica e histórica de ser mais.

A educação libertadora tem, fundamentalmente, como objetivo desenvolver a consciência crítica capaz de perceber os fios que tecem a realidade social e superar a ideologia da opressão. Na verdade, esse não é objetivo dos opressores que tentam manter, por meio da educação bancária, a reprodução da consciência ingênua, acrítica. Na educação como prática da liberdade, os homens e as mulheres são vistos como "corpos conscientes", e se tem convicção profunda no poder criador do ser humano como sujeito da história - uma história inacabada, construída a cada instante, cujo processo de conhecer envolve intercomunicação, intersubjetividade. Os protagonistas do processo são os sujeitos da educação - estudante e professor(a) -, que, jun- 
tos, dialogam, problematizam e constroem o conhecimento. Por isso, problematizar, na perspectiva freireana, é exercer análise crítica sobre a realidade das relações entre o ser humano e o mundo, o que requer os sujeitos se voltarem, dialogicamente, para a realidade mediatizadora, a fim de transformá-la, o que só é possível por meio do diálogo, "desvelador da realidade".

Essa atitude dialógica, conforme Paulo Freire, permite a reflexão crítica dos homens e das mulheres em suas relações com o mundo para sua libertação autêntica. "É práxis, que implica na ação e na reflexão dos homens sobre o mundo para transformá-lo" (Freire, 2001, p. 67). Portanto, nega o ser humano abstrato, desligado do mundo, assim como também nega o mundo como uma realidade ausente dos homens e das mulheres e considera que, somente na comunicação, tem sentido a vida humana. Dessa forma, tanto o(a) professor(a) quanto o(a) estudante tornam-se investigadores críticos, rigorosamente curiosos, humildes e persistentes: “[...] a sala de aula libertadora é exigente, e não permissiva. Exige que você pense sobre as questões, escreva sobre elas, discuta-as seriamente" (Freire; Shor, 2008, p. 25). Concordando com Freire (1980, p. 39),

é preciso que a educação esteja - em seu conteúdo, em seus programas e em seus métodos - adaptada ao fim que se persegue: permitir ao homem chegar a ser sujeito, construir-se como pessoa, transformar 0 mundo, estabelecer com os outros homens relações de reciprocidade, fazer a cultura e a história.

Nessa direção, docentes-discentes carregam a possibilidade de compreender suas relações com o mundo, não mais como realidade estática, mas como realidade em transformação, em processo; assim, são estimulados a enfrentar a realidade como sujeitos da práxis, da reflexão e da ação verdadeiramente transformadora da realidade.

Santiago (2006), referindo-se às questões curriculares, ressalta que o pensar freireano traz conceitos fundamentais para teorização sobre o currículo. E destaca o diálogo entre as categorias fundantes do pensar freireano como princípio que pode colaborar na formulação da base teórico-metodológica do currículo e do desenvolvimento de práticas pedagógicas. Discutiremos, a seguir, a contribuição dessa categoria como princípio e fundamento do currículo. 


\section{Diálogo: princípio e fundamento da educação como prática da liberdade}

O diálogo, em Paulo Freire, favorece o pensar crítico-problematizador das condições existenciais e implica uma práxis social na qual ação e reflexão estão dialeticamente constituídas. A liberdade de homens e mulheres expressarem as suas ideias, o que pensam e por que pensam, junto com o outro, provoca a interação e a partilha de diferentes concepções que impulsionam um pensar crítico-problematizador da realidade. Esse movimento gera a necessidade de intervenção no nível das ações, visto que, na perspectiva freireana, a palavra verdadeira é práxis social comprometida com a ação transformadora.

De acordo com o autor, a partir da prática dialógica, o sujeito desenvolve suas potencialidades de comunicar, interagir, administrar e construir o seu conhecimento, melhorando sua capacidade de decisão, humanizando-se. Na prática do diálogo, os homens e as mulheres exercitam o respeito às posições do outro; ela é o caminho para a formação da personalidade democrática. Assim, “o diálogo libertador é uma comunicação democrática, que invalida a dominação e reduz a obscuridade, ao afirmar a liberdade dos participantes de refazer sua cultura" (Freire; Shor, 2008, p. 123).

Para Paulo Freire, o diálogo é construção teórica, atitude e prática pedagógica. É relação objetividade-subjetividade, tem fundamento e conteúdo; portanto, é uma categoria teórica. Como atitude e prática pedagógica, requer reciprocidade na atitude de fala e escuta e tem como fundamento o amor, a tolerância, a humildade e a esperança.

Na prática dialógica, Freire ressalta que a atitude de escuta é tão importante quanto a fala, pois o sujeito que escuta sabe que o que tem a dizer tem valor semeIhante à fala dos outros. Desse modo, o saber escutar refere-se não apenas a silenciar para dar a vez à fala do outro, mas também a estar na posição de disponibilidade, de abertura às diferenças. Isso não se assemelha à aceitação incondicional, a tudo o que o outro pensa e diz, mas é o exercício da escuta sem preconceitos que possibilita a reflexão crítica e o posicionamento consciente.

Assim sendo, as pessoas em situação de fala-escuta assumem posição de reciprocidade: quem fala quer ser ouvido, compreendido, respeitado; quem escuta também quer ter sua oportunidade de falar com as mesmas condições e iguais direitos. Essas situações ampliam as competências comunicativas necessárias para a convivência democrática na sociedade contemporânea, as situações pedagógicas, e qualifica a relação docente-discente, pois o diálogo implica ausência do autoritarismo e, ao mes- 
mo tempo, modos de lidar com a tensão permanente entre a autoridade e a liberdade.

Em Freire (2003, p. 117), o silêncio ocupa lugar de destaque no diálogo, é fundamento, como pode ser visto em suas palavras:

A importância do silêncio no espaço da comunicação é fundamental. De um lado, me proporciona que, ao escutar, como sujeito e não como objeto, a fala comunicante de alguém, procure entrar no movimento interno do seu pensamento, virando linguagem; de outro, torna possível a quem fala, realmente comprometido com comunicar e não com fazer puros comunicados, escutar a indagação, a dúvida, a criação de quem escutou. Fora disso, fenece a comunicação.

O amor também é o fundamento do diálogo. Diz Paulo Freire (2001, p. 80), “[...] se não amo o mundo, se não amo a vida, se não amo os homens, não me é possível o diálogo". Mas não se trata, segundo o autor, de um sentimento ingênuo ou romântico de afeição, ele se caracteriza por relações autênticas de respeito, tolerância e empatia entre pessoas que compartilham ideais na busca da humanização. 0 diálogo só é possível com humildade, pois, quando existe o sentimento de que cada um acredita ser superior ao outro, esses não podem tornar-se companheiros de "pronúncia do mundo". O dialogo requer confiança, fé no outro. Para Paulo Freire (2001, p. 81) “não há também diálogo, se não há uma intensa fé nos homens. Fé no seu poder de fazer e de refazer, de criar e recriar". Em outros termos, são condições para a prática do diálogo: escuta, silêncio, crença no outro, respeito. Alia-se a essas condições a esperança crítica, mobilizadora do diálogo.

Portanto, fundamentam o diálogo: o amor, a tolerância, a humildade e a capacidade de escuta como conteúdo e atitude da prática educativa. A esperança crítica, por sua vez, move o diálogo, pois o sujeito inacabado e consciente do inacabamento tem uma prática dialógica, porque acredita na transformação da realidade, ou seja, “[...] a esperança é um condimento indispensável à experiência histórica. Sem ela, não haveria história, mas puro determinismo" (Freire, 2003, p. 72). Para a relação dialógica ser estabelecida, um clima de abertura, de participação é condição necessária.

O diálogo, ao ser alicerçado no amor, na humildade, na fé no ser humano, na esperança crítica e na participação, estabelece relação horizontal de simpatia e vivência, marcada pela confiança entre os sujeitos. A quebra dessa experiência dá 
lugar ao antidiálogo, caracterizado pela ausência dos fundamentos do diálogo. Ele “[...] é desamoroso. É acrítico e não gera criticidade, exatamente porque desamoroso. Não é humilde. É desesperançoso. Arrogante. Auto-suficiente” (Freire, 2008a, p. 116). Portanto, é o inverso da contribuição freireana, é a situação superada pela construção da atitude dialógica.

É essa configuração que confere importância ao diálogo para a formação de sujeitos autônomos, conscientes, não conformados com a atual realidade social. Por isso a ênfase dada por Paulo Freire à palavra como práxis. Na perspectiva freireana, a palavra é práxis, é ação transformadora no mundo e do mundo. 0 diálogo é a condição de existir humanamente; com ele, os seres humanos se solidarizam, refletem e agem juntos como sujeitos no mundo que querem transformar, humanizar. Vejamos a partir do próprio Paulo Freire (1980, p. 82):

0 diálogo é o encontro entre os homens, mediatizados pelo mundo, para designá-lo. Se, ao dizer suas palavras, ao chamar ao mundo, os homens o transformam, o diálogo impõe-se como o caminho pelo qual os homens encontram seu significado enquanto homens, o diálogo é, pois, uma necessidade existencial.

Vivenciar a liberdade e construir o pensamento crítico requer que as palavras trabalhadas nas instituições escolares não sejam apenas "palavras da escola”, mas "palavras da realidade", em que os acontecimentos do mundo, a dinâmica da vida com suas lutas e possibilidades, bem como as experiências dos(as) estudantes, sejam analisados e articulados com os diferentes tipos de conhecimentos.

Caminhamos com Scocuglia (2005), quando esse destaca que o diálogo é um dos pilares para o processo permanente de construção e reconstrução curricular, assim como o são a consciência e o conhecimento. Acrescenta o autor que um dos caminhos na busca da consciência crítica e reflexiva, nessa construção democrática, é o envolvimento de todos(as) os(as) protagonistas do processo educativo por meio da vivência da prática dialógica. Logo, a dinâmica de pensar e formular o currículo, alicerçada no conhecimento-consciência-diálogo “[...] abriria possibilidades concretas para que os currículos educacionais ganhassem continuamente criticidade e qualidade, e contribuíssem (na própria ação constante 'em serviço’ de refazê-lo) para a reeducação do coletivo que faz a educação e a escola”' (Scocuglia, 2005, p. 87). 
Resumindo, Scocuglia (2005), com base em Paulo Freire, aponta como eixos norteadores na construção de propostas curriculares o conhecimento, a consciência crítica da realidade e a prática dialógica, ao levar em consideração que os homens e as mulheres têm direito a conhecer o que não conhecem, a conhecer melhor o conhecimento que já possuem e a construir o seu próprio conhecimento. Em decorrência, contribui no processo de construção da consciência crítico-reflexiva, caracterizada pela análise em profundidade dos problemas e reafirma o lugar de participação dos sujeitos na construção do currículo mediante o exercício de diálogo.

Aproximando-se mais do lugar da vida curricular, Saul e Silva (2009) ressaltam que, para pensar o currículo coerente com os princípios freireanos, temos como desafio a democratização da gestão das unidades escolares para construir uma escola pública com qualidade social, onde o processo de elaboração/reformulação curricular seja uma construção coletiva, vivenciada em uma dinâmica de diálogos com a participação dos diferentes sujeitos envolvidos na ação educativa. Por isso, é importante assumir que os sujeitos são agentes da práxis curricular e ponto de partida das situações reais para problematizá-las e avançar na construção de um conhecimento crítico que contribua com uma educação comprometida com a democracia.

Em outras palavras, o diálogo, como fundamento e princípio da proposta educacional libertadora, pode orientar as questões que permeiam a construção do currículo na busca do conteúdo programático da educação, em torno do objeto do conhecimento que o(a) professor(a) vai dialogar com os(as) estudantes.

\section{Diálogo: prática político-pedagógica para a construção do conteúdo programático da educação}

A escolha do conteúdo programático é uma das preocupações que permeiam as discussões no campo do currículo e também nas políticas públicas. Paulo Freire (2005) destaca a impossibilidade de existir uma prática educativa sem conteúdo, ou seja, sem objeto do conhecimento, e justifica, afirmando que a prática educativa é naturalmente gnosiológica. É importante que o ensino dos conteúdos esteja associado a uma leitura crítica da realidade que desvele a razão dos inúmeros problemas sociais. A escolha do conteúdo programático é de natureza política, pois “[...] tem que ver com: que conteúdos ensinar, a quem, a favor de quê, de quem, contra quê, contra quem, como ensinar. Tem que ver com quem decide sobre que conteúdos ensinar" (Freire, 2005, p. 45). 
Freire aponta princípios norteadores para a construção de um currículo que atenda aos pressupostos da educação libertadora, destaca a relevância do conteúdo programático e marca o lugar do conteúdo da educação no currículo crítico.

Os conteúdos não podem ser pedaços de uma realidade, desconectados da totalidade. Daí a importância de se propor aos(às) estudantes aspectos, situações significativas de sua realidade cuja análise crítica permita reconhecer a interação de suas partes, para que, então, eles(as) possam compreender a totalidade, e os conteúdos ganhem significado. Nesse sentido, argumenta que

\begin{abstract}
a questão fundamental, neste caso, está em que, faltando aos homens uma compreensão crítica da totalidade em que estão, captando-a em pedaços nos quais não reconhecem a interação constituinte da mesma totalidade, não podem conhecê-la. E não o podem porque, para conhecê-la, seria necessário partir do ponto inverso. Isto é, lhes seria indispensável ter antes a visão totalizada do contexto para, em seguida, separarem ou isolarem os elementos ou as parcialidades do contexto, através de cuja cisão voltariam com mais claridade à totalidade analisada (Freire, 2001, p. 96).
\end{abstract}

O conteúdo programático da educação, assim, não é um conjunto de informações que deve ser depositado nos(as) estudantes, contido em programas organizados exclusivamente por gestores(as) ou professores(as) de acordo com a concepção bancária de educação. "Numa visão libertadora, [...] o seu conteúdo programático já não involucra finalidades a serem impostas ao povo, mas, pelo contrário, porque parte e nasce dele, em diálogo com os educadores, reflete seus anseios e esperanças" (Freire, 2001, p. 102-103).

O conteúdo crítico é buscado, dialogicamente, com o(a) estudante e construído a partir da sua visão de mundo. O(a) professor(a), por meio de contradições básicas da situação existencial, problematiza a realidade concreta, desafia os(as) estudantes para que busquem respostas no nível intelectual e no nível da ação. Nessa realidade mediatizadora, o conteúdo programático da educação pode ser construído, ou seja, “[...] será a partir da situação presente, existencial, concreta, refletindo o conjunto de aspirações do povo, que poderemos organizar o conteúdo programático da educação ou da ação política” (Freire, 2001, p. 86).

Na perspectiva do currículo emancipatório, a tarefa da escola não se restringe 
a ensinar conteúdos disciplinares, mas deve também desmitificar a realidade para provocar a ação consciente. Daí a importância de a organização curricular estar fundamentada nas relações da vida cotidiana.

Na mesma linha de compreensão, Saul e Silva (2009, p. 236), ao tratarem das questões curriculares coerentes com os princípios de construção de conhecimento próprios da pedagogia freireana, chamam atenção para a importância de os conteúdos programáticos serem compreendidos como um "[...] acervo científico acumulado pela humanidade a serviço do esclarecimento crítico necessário à emancipação dos sujeitos". Para tanto, os conteúdos precisam ser problematizados em um processo dinâmico e dialógico com os temas e as situações da vida, na realidade concreta, objetivando uma análise crítica dessa realidade para avançar na compreensão das situações e formular soluções praticáveis. Eis o lugar do diálogo:

[...] o diálogo seria propulsor, em sua vertente pedagógica crítica, de um movimento cognitivo e político-epistemológico contínuo, suscitando necessidades de apreender conhecimentos pertinentes às temáticas da realidade abordadas, motivando a construção de novos referenciais analíticos (Saul; Silva, 2009, p. 234).

Nessa direção, a seleção e a organização do conteúdo programático solicitam um trabalho conjunto de pesquisa do universo temático dos(as) estudantes ou do conjunto de seus temas geradores. Os temas geradores se referem às temáticas significativas, vivenciadas nas relações homens-mundo, ou seja, as temáticas se encontram nos homens e nas mulheres inseridos na sua realidade concreta. Assim, “[...] investigar o tema gerador é investigar o pensar dos homens referido à realidade, é investigar seu atuar sobre a realidade, que é sua práxis" (Freire, 2001, p. 98).

É com essa compreensão que Freire (2008a) ressalta a importância do estudo da cultura do ser humano como conteúdo programático da educação, uma vez que possibilita a homens e mulheres distinguirem os dois mundos - o da natureza e o da cultura - e, assim, perceberem o seu papel ativo na sociedade e com a realidade.

Assim sendo, cultura é o produto criativo da atividade humana que se manifesta nos gestos mais simples da vida diária. Os sujeitos letrados e iletrados produzem cultura na medida em que, ao interferir e transformar os elementos ao seu redor, criam e recriam, alterando e dominando continuamente a natureza, dinamizando e 
humanizando a sua realidade. Com tal compreensão, não existe cultura pior ou meIhor, cultura erudita e cultura popular, mas diferentes expressões culturais, por isso faz sentido falar em culturas. Para Freire (2008a, p. 117, grifo do autor),

a cultura como o acrescentamento que o homem faz ao mundo que não fez. A cultura como o resultado de seu trabalho. De seu esforço criador e recriador. 0 sentido transcendental de suas relações. A dimensão humanista da cultura. A cultura como aquisição sistemática da experiência humana. Como uma incorporação, por isso crítica e criadora, e não como uma justaposição de informes ou prescrições "doadas".

Segundo Freire e Faundez (2002), o conceito de cultura está relacionado ao de diferença e tolerância, pois, na relação com o outro, é preciso compreender que o diferente se torna essencial. Sendo assim, faz-se necessário respeitar a cultura diferente, a fim de o diálogo enriquecedor entre as diversas expressões culturais ser estabelecido. Essa atitude de respeito revela amadurecimento quando se vivenciam as diferenças culturais. No entanto, para isso ocorrer, é importante o desenvolvimento da tolerância no sentido de admitir nos outros maneiras de pensar, de agir e de sentir distintas das nossas.

Contribuindo com essa ideia, Giroux e Simon (2008) afirmam ser necessário, em qualquer discussão sobre pedagogia e educação na perspectiva crítica, trabalhar o conceito de diferença, pois entendem as práticas culturais populares como processos vividos por diferentes grupos, na vida cotidiana, que refletem a capacidade criativa e, por vezes, inovadora das pessoas. Entretanto, os autores ressaltam que, apesar de vários estudos em torno das diferentes expressões culturais, a cultura popular é vista como algo inferior, indigna de legitimação acadêmica, por situar-se no terreno do cotidiano. Freire e Faundez (2002), ao refletirem sobre essa questão, destacam a importância da cotidianidade nos processos educacionais, buscando a valorização da cultura popular, por permitir que cada um seja sujeito dentro da experiência pedagógica que procura, nas diferenças e na vida cotidiana, questões problematizadoras para o contexto de sala de aula. De acordo com Freire (2008b, p. 64),

[...] o homem vai dinamizando o seu mundo a partir destas relações com ele e nele; vai criando, recriando; decidindo. Acrescenta algo ao mundo 
do qual ele mesmo é criador. Vai temporalizando os espaços geográficos. Faz cultura. E é o jogo criador destas relações do homem com o mundo o que não permite, a não ser em termos relativos, a imobilidade das sociedades nem das culturas.

No pensamento freireano, todo ser humano é construtor de conhecimento; portanto, produtor de cultura. Sendo assim, é importante que os processos educativos ofereçam aos(às) estudantes oportunidades de confrontar seus conhecimentos com informações mais amplas, consistentes e significativas para a construção e ou reconstrução de novos conhecimentos mediante o diálogo crítico.

Dessa forma, a ação educativa fundada na prática dialógica, além de possibilitar ao(à) estudante maior poder social e de intervenção para transformar as situações menos humanas em mais humanas, pode permitir aos sujeitos a busca constante de ações e reações de solidariedade, respeito e responsabilidade com eles mesmos, com os outros e com o mundo (Souza, 2007).

Nesse contexto, o conhecimento produzido será um conhecimento capaz de contribuir para a construção de uma sociedade mais igualitária, pois o ato educativo permitirá a identificação de contradições e alternativas para a transformação da realidade social. Sendo assim, reconhecer a importância da prática dialógica na construção do conteúdo da ação educativa possibilita diferentes maneiras de formular e organizar o currículo na perspectiva libertadora.

\section{Considerações finais}

Neste texto procuramos evidenciar que o pensamento político-pedagógico de Paulo Freire está sempre em movimento e dialoga com diferentes questões contemporâneas, assim como traz elementos norteadores para a construção da teoria curricular emancipatória e eticamente comprometida com a humanização dos sujeitos. Assim, a análise dos elementos que configuram a proposta educacional libertadora e a categoria diálogo, uma categoria fundante do pensar freireano, pode contribuir para a construção dos processos de formulação de políticas e práticas curriculares ancorados em princípios democráticos que possibilitam o processo participativo dos sujeitos reconhecendo suas relações.

A concepção de educação emancipatória, na perspectiva freireana, visa ao desenvolvimento da consciência crítica para a formação de sujeitos competentes, capazes 
de exercer sua participação cidadã - educação comprometida com a humanização que possibilita romper com a relação verticalizada entre professor(a) e estudante. A prática pedagógica, decorrente desses princípios caracterizadores da educação libertadora, rejeita a neutralidade do processo educativo, concebe a educação como dialógica, valoriza a horizontalidade de saberes e propicia ao(à) estudante desenvolver o pensar crítico acerca da sua realidade.

Paulo Freire atribui à Educação o papel de contribuir para o processo de transformação social, pois, para ele, a educação é dialógico-dialética, na medida em que o ato educativo pode superar a prática de dominação e construir uma prática da liberdade em que educador(a) e educando(a) são os protagonistas do processo, dialogam e constroem o conhecimento mediante a análise crítica das relações entre os sujeitos e o mundo. Esse movimento decorre da compreensão da Educação como ato de conhecimento e como ato político. Sendo assim, ele vê na educação a possibilidade de emancipação humana para superar as diferentes formas de opressão e dominação existentes na sociedade contemporânea, marcada por políticas neoliberais e excludentes.

Essa concepção de educação contribui para a fundamentação de um currículo que possibilite a conscientização pelos sujeitos dos condicionantes das estruturas sociais que alienam e oprimem - currículo pautado na compreensão de mundo, de ser humano e de sociedade como unidade dialética, os quais se movem na inter-relação de complementaridade.

Os elementos político-pedagógicos da educação libertadora e os fundamentos da prática dialógica contribuem para estabelecer uma relação dialética entre o currículo e o contexto histórico, social, político e cultural, ou seja, para superar a concepção técnico-linear de currículo e tratá-lo na dimensão da totalidade em que os diferentes contextos, num processo dinâmico, se relacionam e se influenciam. Essa compreensão crítico-emancipatória possibilita pensar o currículo na direção de um projeto social que pode colaborar para a emancipação dos homens e das mulheres, assim como, subsidiar a orientação de novos caminhos para a elaboração de políticas curriculares comprometidas com ações educativas coerentes com a proposta educacional libertadora. 


\section{Referências bibliográficas}

BARDIN, Laurence. Análise de conteúdo. 5. ed. Lisboa-Portugal: Edições 70, 2008, $280 \mathrm{p}$.

FREIRE, Paulo. A educação na cidade. 6. ed. São Paulo: Cortez, 2005. 144 p.

FREIRE, Paulo. Conscientização: teoria e prática da libertação - uma introdução ao pensamento de Paulo Freire. 4. ed. São Paulo: Moraes, 1980. 102 p.

FREIRE, Paulo. Educação como prática da liberdade. 31. ed. Rio de Janeiro: Paz e Terra, 2008a. $158 \mathrm{p}$.

FREIRE, Paulo. Educação e mudança. 31. ed. Rio de Janeiro: Paz e Terra, 2008b. 79 p.

FREIRE, Paulo. Pedagogia da autonomia: saberes necessários à prática educativa. 28. ed. São Paulo: Paz e Terra, 2003. 148 p.

FREIRE, Paulo. Pedagogia do oprimido. 31. ed. Rio de Janeiro: Paz e Terra, 2001. 184 p.

FREIRE, Paulo. The politics of education: culture, power, and liberation. Westport, CT: Bergin and Garvey, 1985. 209 p.

FREIRE, Paulo; FAUNDEZ, Antonio. Por uma pedagogia da pergunta. 5. ed. Rio de Janeiro: Paz e Terra, 2002. 158 p.

FREIRE, Paulo; SHOR, Ira. Medo e ousadia: o cotidiano do professor. 12. ed. Rio de Janeiro: Paz e Terra, 2008. 224 p.

GIROUX, Henry. Teoria crítica e resistência em educação: para além das teorias de reprodução. Petrópolis: Vozes, 1986. 336 p.

GIROUX, Henry; SIMON, Roger. Cultura popular e pedagogia crítica: a vida cotidiana como base para o conhecimento curricular. In: MOREIRA, Antônio Flávio; SILVA, Tomaz Tadeu da. (Org.). Currículo, cultura e sociedade. 10. ed. São Paulo: Cortez, 2008. p. 93124 .

SANTIAGO, Maria Eliete. Formação, currículo e prática pedagógica em Paulo Freire. In: BATISTA NETO, José; SANTIAGO, Eliete. (Org.). Formação de professores e prática pedagógica. Recife: Massangana, 2006. p. 73-84.

SANTOS. Lucíola de Castro Paixão; MOREIRA, Antônio Flávio. Currículo: questões de seleção e de organização do conhecimento. In: TOZZI, Devanil et al. Currículo, conhecimento e sociedade. São Paulo: Fundação para o Desenvolvimento da Educação, 1995. p. 47-63.

SAUL, Ana Maria. A construção do currículo na teoria e prática de Paulo Freire. In: APPLE, Michael; NÓVOA, António (Org.). Paulo Freire: política e pedagogia. PortoPortugal: Porto Editora, 1998. 192 p. 
SAUL, Ana Maria; SILVA, Antonio Fernando Gouvêa. O legado de Paulo Freire para as políticas de currículo e para a formação de educadores no Brasil. Revista Brasileira de Estudos Pedagógicos, Brasília, v. 90, n. 224, p. 223-244, jan./abr. 2009.

SCOCUGLIA, Afonso Celso. As reflexões curriculares de Paulo Freire. Revista Lusófona de Educação [on-line], Lisboa, n. 6, p. 81-92, 2005. Disponível em: 〈http://www.scielo.oces.mctes.pt/scielo.php?script=sci_arttext\&pid=S1645725020 05000200007\&lng=pt\&nrm=iso〉. Acesso em: 05 jan. 2013.

SILVA, Tomaz Tadeu da. Documentos de identidade: uma introdução às teorias do currículo. 2. ed. Belo Horizonte: Autêntica, 2007.154 p.

SOUZA, João Francisco de. E a educação popular: ¿¿ Quê ?? Uma pedagogia para fundamentar a educação, inclusive escolar, necessária ao povo brasileiro. Recife: Bagaço, 2007. 424 p.

YOUNG, Michael. Currículo e democracia: lições de uma crítica à “Nova sociologia da Educação”. Educação \& Realidade, Porto Alegre, v. 14, n. 1, p. 29-40, jan./jun. 1989.

Submetido à avaliação em 15 de janeiro de 2014. Aprovado para publicação em 28 de agosto de 2014 . 